\title{
Recent developments in the preparation of nano-gold composite coatings
}

Renate Freudenberger, Andreas Zielonka, Martin Funk, Paul Servin, Rainer Haag, Teodora Valkova and Uwe Landau

www.goldbulletin.org

\begin{abstract}
New possibilities in the design of gold-containing electrochemical coating systems for electronic applications are given by the incorporation of gold-nanoparticles in metal-matrix-systems. The major problem for the application of nanoparticles is the strong agglomeration of the particles in the electrolyte solutions, preventing the incorporation of nanoscaled dispersants.
\end{abstract}

A complete new concept for the deposition of nano dispersion layers, overcoming this agglomeration challenge, is the application of core shell systems. Using these systems, it becomes possible for the first time to incorporate metal nanoparticles into electrodeposited metal layers to form metal nanoparticle metal matrix systems (MNP-MMS). The advantage of such layers is to form nanocomposite materials far away from the thermodynamic equilibrium. Especially for the combination of gold nanoparticles with a nickel matrix, a way is shown for the manufacturing of temperature-stable nanocomposite structures, because at least in the temperature range of electronic applications no loss of the dispersive character by diffusion processes is expected. By incorporating the precious metal material into the nickel matrix as the main electrodeposit, and reducing the top gold layer thickness, a possible way of reducing the gold consumption and an economic use of gold resources is shown.

\section{Introduction}

Surface technology is a main part of the quality aspects like corrosion resistance, wear resistance, tribological properties and decorative appearance. By the deposition of components with a proper coating, a large enhancement of the product performance is possible. Besides the great need for miniaturisation and weight reduction, electronic components in automotive applications should meet the demands for a higher wear and corrosion resistance even at temperatures of more than $200^{\circ} \mathrm{C}$. Therefore new contact materials and coating systems have to be developed in order to increase the thermal stability, to reduce the friction of multipole connectors, and in general to reduce the wear of these components for a better function, durability, and reliability of modern vehicles. The development of metal nanoparticles metal matrix systems using gold nanoparticles is a possible approach for this application.

The incorporation of particles into electrodeposited metals or alloys in form of a dispersion layer has widely been investigated for micro- and nanoscaled particles, e.g. $\mathrm{SiC}, \mathrm{ZrO}_{2}, \mathrm{TiO}_{2}, \mathrm{TiN}, \mathrm{Al}_{2} \mathrm{O}_{3}$, and diamonds, in order to increase the wear resistance of the material. Besides the effect of the hard particles in the soft metal matrix onto the mechanical properties, it was also shown, that nanoparticles in the electrolyte can strongly influence the electrochemical process by an inhibiting effect and by a change of the crystallographic structure of the matrix material.

\section{Gold nanoparticles}

The application of core shell systems with a core of gold nanoparticles and polymer shells around is a completely new concept for the deposition of nano composite films [1]. The advantage of such layers 
is the possibility to form composite material far away from thermodynamic equilibrium conditions. The base for the core shell architecture are hyper branched dendritic polymers, like polyethyleneiminepolyamidoamine (PEI-PAMAM) used for the reaction with gold nanoparticles. After the reaction of PEIPAMAM with gold ions, a stable clear solution of metallic gold nanoparticles is formed, which has a high long term stability even with high ionic strengths, depending on the molar ratio between polymer and the gold particles. The clear red colour of the solutions caused by surface plasmon resonance effect is an indicator for the existence of the gold nanoparticles.

\section{Polymer synthesis}

For the incorporation of gold nanoparticles into nickel layers, a polyethyleneimine polyamidoamine (PEI-PAMAM) structure was used [2]. Figure 1 and figure 2 show the structure of polyethyleneimine (PEI) and PEI-PAMAM.

The synthesis, which was first reported by Krämer et. al., has been optimized for large-scale production. To a solution of $33.6 \mathrm{~g} \mathrm{PEI} \mathrm{(25} \mathrm{kDa,} 23.3 \mathrm{mmol} / \mathrm{g}$ $\mathrm{N}-\mathrm{H}$ ) in $100 \mathrm{ml} \mathrm{MeOH}$, heated to $50^{\circ} \mathrm{C}$, was dropwise added $113 \mathrm{ml}(1.24 \mathrm{~mol})$ acrylic acid methyl ester. The reaction product was left stirring for 2 hours before it was precipitated into an ether/pentane

Figure 1

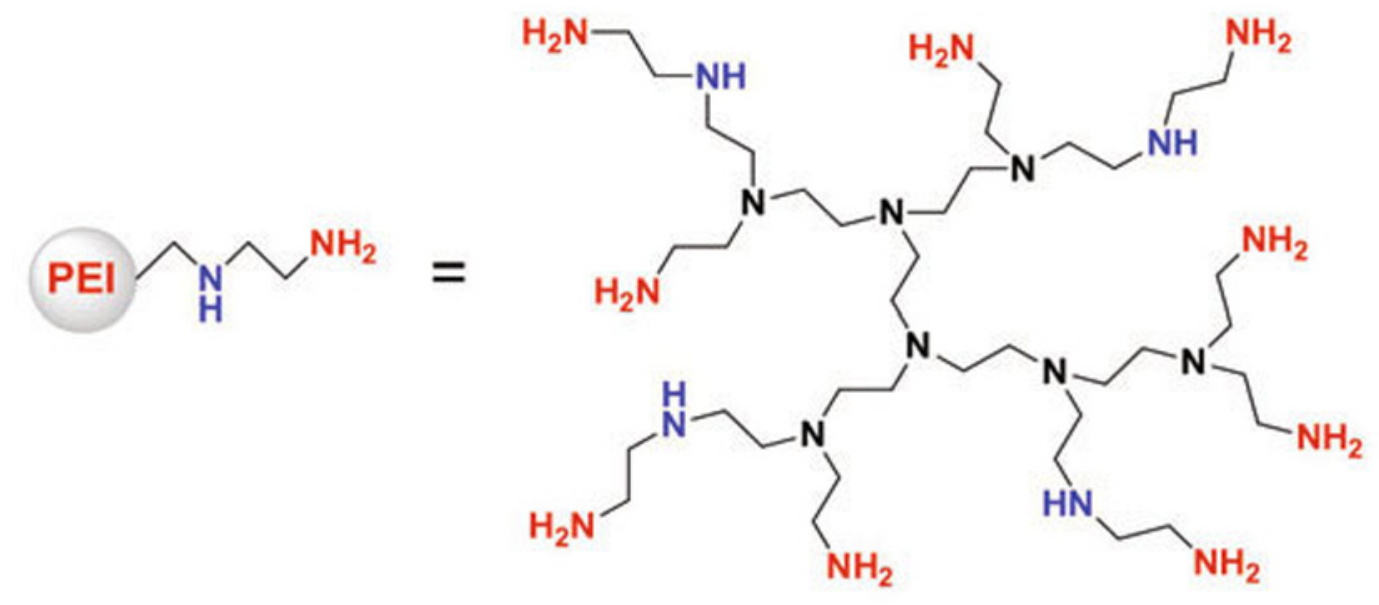

Structure of polyethyleneimine (PEI)

Figure 2

PEI<smiles>CCCNCCN</smiles>

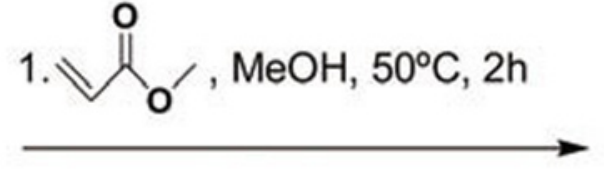

2. ${ }^{\mathrm{H}_{2} \mathrm{~N}} \widehat{\mathrm{NH}}_{2}, \mathrm{MeOH}, 50^{\circ} \mathrm{C}, 22 \mathrm{~h}$ 


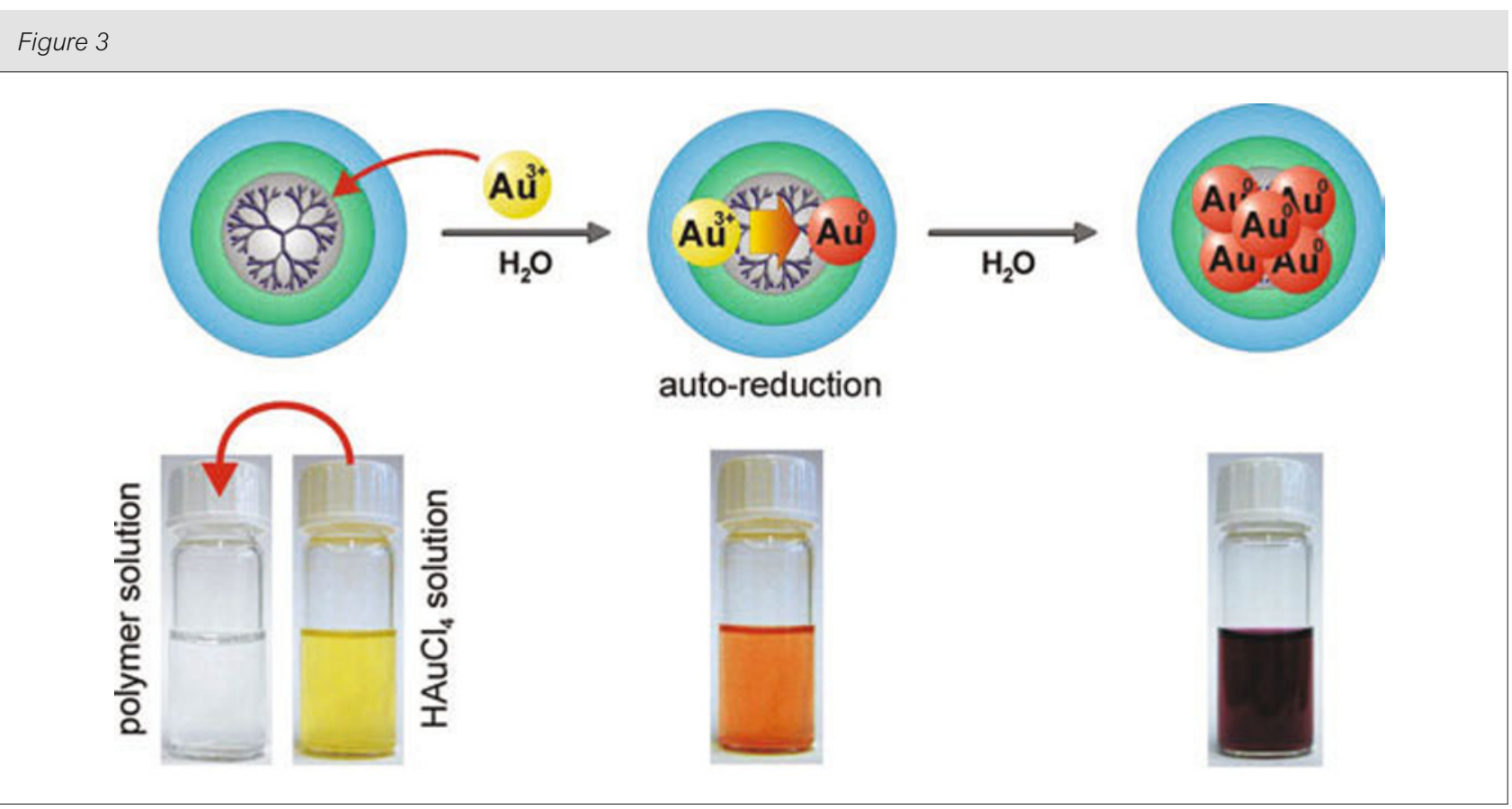

Synthesis of gold nanoparticles

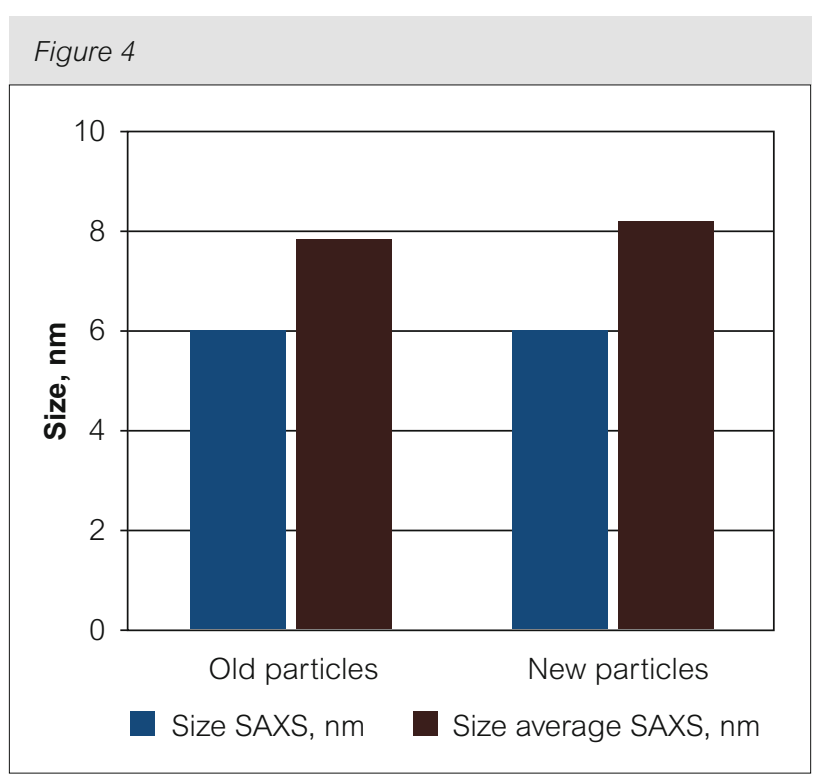

Size of the gold nanoparticles (SAXS measurement)

mixture $(4: 1)$ twice and dried on high vacuum. The product, which was a pale yellow oil, was obtained in a yield of $84 \%(84.7 \mathrm{~g})$. For the second reaction step, the raw product was dissolved in $160 \mathrm{ml} \mathrm{MeOH}$ and was dropped to $236 \mathrm{ml}$ (3.53 mole) ethylendiamine, heated to $50^{\circ} \mathrm{C}$, within 2 hours. The reaction mixture was left stirring for 22 hours before it was precipitated into an ether/pentane mixture (4:1) twice and dried on high vacuum. The pale yellow and highly viscous product was obtained in a yield of $87 \%(92.8 \mathrm{~g})$.

\section{Synthesis of the metal nanoparticles}

For the synthesis of the metal nanoparticles, the polymer and the metal salts $\left(\mathrm{HAuCl}_{4}\right.$ resp.) are separately dissolved and mixed together by adding the metal salt solution to the polymer solution. The metal ions are then reduced by the addition of a reducing agent, e.g. $\mathrm{NaBH}_{4}$. For the synthesis of gold nanoparticles, the addition of a reducing agent is not necessary since an auto-reduction takes place. Figure 3 shows the encapsulation and reduction of gold for the production of the gold nanoparticles, stabilized at a particle size of less than $10 \mathrm{~nm}$.

\section{The particle size of metal nanoparticles}

The particle size of the metal nanoparticles was measured by small angle $x$-ray scattering (SAXS). Figure 4 shows the measurement results in a comparison of two different gold nanoparticles samples. One of the samples had been stored for 7 months before measurement, the second sample, which had been prepared in the same way, was measured immediately after its synthesis. In both samples, most of the nanoparticles have a particles size of $6 \mathrm{~nm}$ (blue bars). In some cases, particle sizes up to $10 \mathrm{~nm}$ are found, probably generated by Ostwald ripening. Over all particle sizes measured, an average of $8 \mathrm{~nm}$ is obtained. 


\section{Stability of the PEI-PAMAM polymer in electrolyte solutions}

The long term stability of the solution depends on the molar ratio between polymer and gold. The molar ratio was changed in the range from 1:16 to 1:80. Only solutions with a molar ratio up to $1: 30$ showed good long term stability. The clear red colour of the solution is an indicator for the existence of gold nanoparticles. For the use of PEI-PAMAM as a gold nanotransporter in solutions for the electrodeposition of composite layers, it is important to characterise the influence of different electrolyte additives on the chemical stability of the polymer. Additives, typically used for the electrodeposition of nickel and other metal matrix systems, are listed in table 1. These components were added to a PEI-PAMAM solution in water, with maximum concentrations of the additives given in the table. Water was used as solvent for a better visibility of possible precipitations. Even after a storage time of 4 weeks, the metal nanoparticle size did not change with the additives present, as light scatter experiments showed. Even after longer storage times, no precipitations were observed, with exception of naphthalene trisulfonic acid (NTS) as electrolyte additives.

Table 1: Additive influence on the polymer stability

\begin{tabular}{|c|c|c|}
\hline Substance & Concentration & Stability \\
\hline Saccharine & $3.0 \mathrm{~g} / \mathrm{L}$ & yes \\
\hline $\begin{array}{l}\text { Naphthalene trisulfonic } \\
\text { acid (NTS) }\end{array}$ & $11.0 \mathrm{~g} / \mathrm{L}$ & no \\
\hline $\begin{array}{l}\text { Sodium dodecylsulfate } \\
\text { (SDS) }\end{array}$ & $2.0 \mathrm{mg} / \mathrm{L}$ & yes \\
\hline Methanesulfonic acid & $1 \mathrm{M}$ & yes \\
\hline Triton X-100 & $2.5 \mathrm{~g} / \mathrm{L}$ & yes \\
\hline Phenolphthaleine & $0.1 \mathrm{~g} / \mathrm{L}$ & yes \\
\hline $\begin{array}{l}\text { 1-(3-sulfopropyl) } \\
\text { pyridinium }\end{array}$ & $1.0 \mathrm{~g} / \mathrm{L}$ & yes \\
\hline
\end{tabular}

Table 2: Nickel sulphamate electrolyte

\begin{tabular}{|c|c|}
\hline Component & Concentration, g/L \\
\hline $\mathrm{Ni}$ as $\mathrm{Ni}\left(\mathrm{NH}_{4} \mathrm{SO}_{3}\right)_{2} \cdot 4 \mathrm{H}_{2} \mathrm{O}$ & $415 \mathrm{~g} / \mathrm{L}(97.2 \mathrm{~g} / \mathrm{L} \mathrm{Ni})$ \\
\hline $\mathrm{Ni}$ as $\mathrm{NiCl}_{2} \cdot 6 \mathrm{H}_{2} \mathrm{O}$ & 35 g/L (9.0 g/L Ni) \\
\hline $\mathrm{H}_{3} \mathrm{BO}_{3}$ & $50 \mathrm{~g} / \mathrm{L}$ \\
\hline $\mathrm{pH}$ & 4.0 \\
\hline
\end{tabular}

\section{Electrochemical measurements}

The electrochemical measurements were performed in an additive-free Nickel electrolyte according to table 2. The reagents were of p.a. grade, dissolved in distilled water. The electrolyte cell (glass) had a volume of $50 \mathrm{~cm}^{3}$. The experimental setup for the electrochemical measurements included rotating disks or copper cylinders as working electrodes (cathodes; 2cm²), rotating at 250-1000 rpm, nickel anodes of electroplating quality, $\mathrm{Ag} / \mathrm{AgCl}(\mathrm{E}=-0.197 \mathrm{~V}$ vs. $\mathrm{NHE})$ as reference electrode, and a potentiostat (Zahner). Potential scan rate was $0.5 \mathrm{Vs}^{-1}$. The copper substrates were pretreated by electrolytic degreasing and pickling before starting the experiments, and pre-coated with an additive and particle-free Nickel layer. The same setup was used for the electroplating experiments.

\section{Characterisation of the nanocomposite coatings}

Analysis by Glow Discharge Optical Emission Spectroscopy (GDOES)

GDOES is a spectroscopic method for the quantitative analysis of metals and non-metal solid matter, also suitable for the analysis of coating systems. A cathodic sputtering process with Argon ions is used to remove material layer by layer from the sample surface. The removed atoms are excited in the plasma and emit a characteristic spectrum, measured by the spectrometer.

\section{Ion beam preparation}

Metallographic cross-sections were prepared in order to examine the particle distribution and layer quality, and investigated with field emission SEM. Because of the high resolution of this SEM type, structural analysis with a quality of unimagined extent is possible nowadays for the characterisation of multi-phased material and metal matrix composites, without the necessity of using TEM. Even with best practice of metallographic techniques, the provision of satisfactory cross-section surfaces is difficult. This is valid not only for standard SEM investigations, but especially for most sensitive electron beam backscatter (EBSD) investigations, giving local phase information and microtextural analysis. By now, external ion beam preparation devices are available, making possible to reach sufficient surface preparation qualities for cross-sections to be examined with field emission SEM. The advantage of this technique compared to internal focused ion 


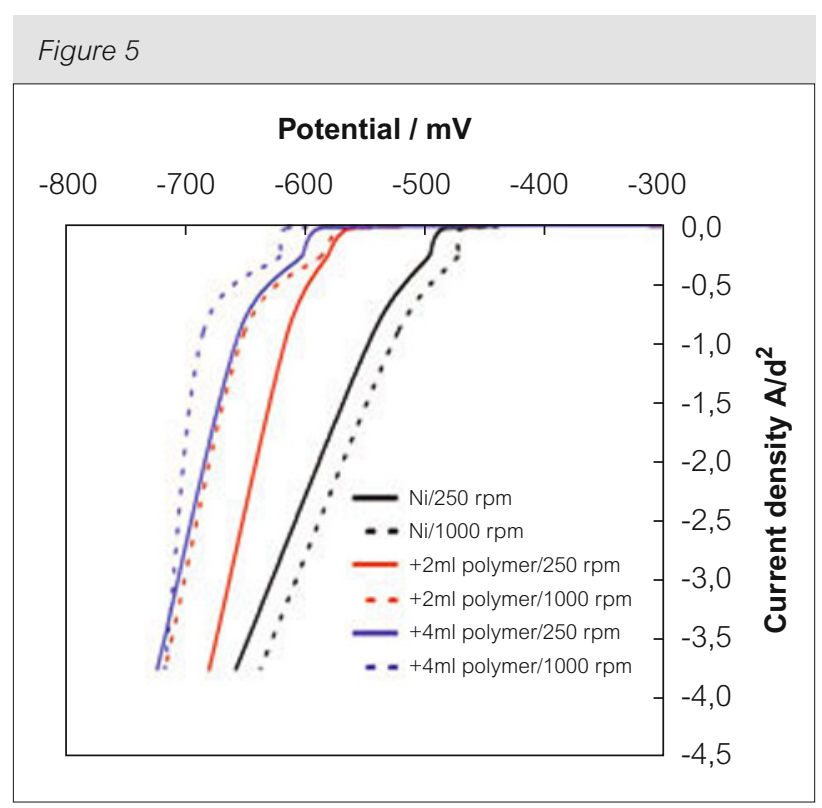

I-E diagrams for pure nickel electrolyte and PEI-PAMAM without gold nanoparticles for different rotations speeds

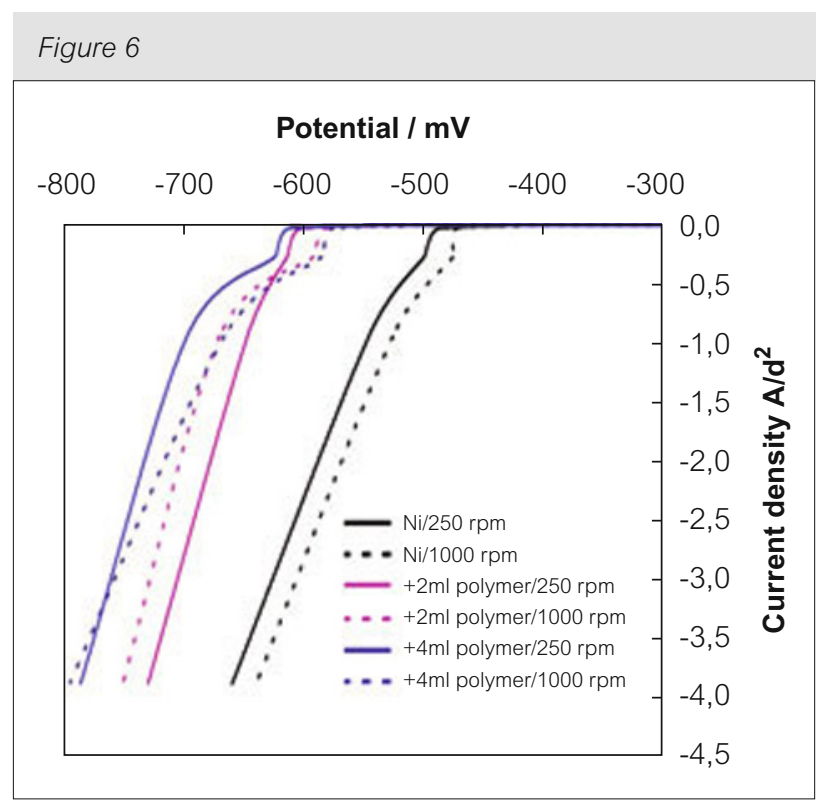

I-E diagrams for pure nickel electrolyte and PEI-PAMAM with gold nanoparticles for different rotations speeds

beam (FIB) preparation, is the relatively large area which can be treated, even parallel to the SEM operation. Depending on the material of matrix or composite, effects like smearing, outbreaks of brittle components, filling of voids and cavities by debris or polishing agents, are avoided. Fine scratches and mechanical deformations are removed, so the interpretation of the cross-section appearance is facilitated. It has to be mentioned that special

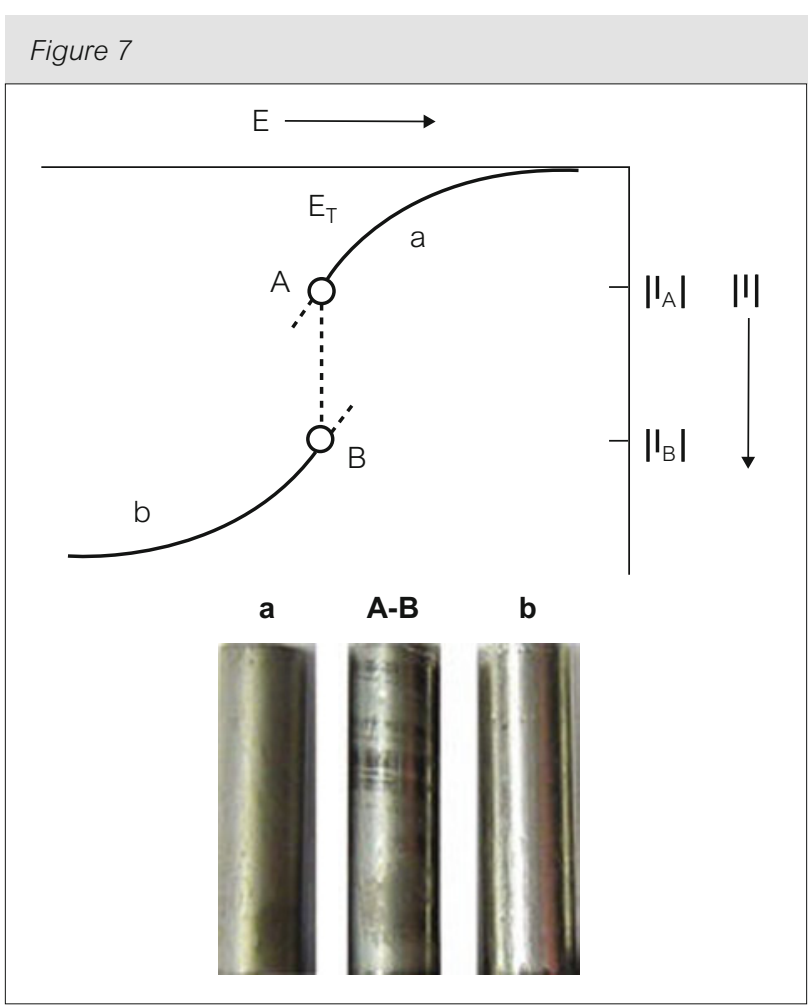

Schematic l-E curves with coexisting states (a - electrodeposition at $0.4 \mathrm{~A} / \mathrm{dm}^{2} / \mathrm{A}-\mathrm{B}-2.0 \mathrm{~A} / \mathrm{dm}^{2}$ / $\left.b-10.0 \mathrm{~A} / \mathrm{dm}^{2}\right)$

embedding compounds have to be used because improper material with high etching rates lead to the formation of slopes and may pretend defects and layers.

\section{l-E-investigations}

The comparison of the potential scan in the pure nickel electrolyte with the electrochemical behaviour after addition of PEI-PAMAM polymer shows the inhibiting effect of the polymer, which is an effect increasing with higher rotation speeds (see Figure 5). A similar behaviour is known from the nickel electrodeposition with 2-butyne-1,4-diol as a levelling agent. The inhibition of the nickel reduction is even stronger, when not only the polymer, but also gold nanoparticles in combination with the PEI-PAMAM polymer are present in the solution (see Figure 6). The potential differences with higher rotation speeds are higher in the presence of the metal nanoparticles.

The nickel electrodeposition with the PEI-PAMAMnano-gold system leads to either homogeneously matte or bright or inhomogeneous surfaces qualities, depending on the applied current densities. These differing appearances may be related to three current density regions. At low current densities, less than 
$1 \mathrm{~A} / \mathrm{dm}^{2}$, the coating surfaces are homogeneously matte. Between 1 and $8 \mathrm{~A} / \mathrm{dm}^{2}$ both matte and bright regions occur on the same sample surface. The percentage of brighter areas is increased with the current density. At a current density higher than $8 \mathrm{~A} / \mathrm{dm}^{2}$, the whole sample surface is bright. This effect of pattern formation is a frequently discussed phenomenon in the electroplating technology [314]. Several studies have been done for better understanding of patternformation of inhomogeneous interfacial potential in electrodissolution reactions [15], electrocatalytic oxidation reactions and electrocatalysis [16]. Pattern formation in electrochemical systems occurs at the electrode/ electrolyte interface and results from the interaction between interfacial kinetics and transport processes parallel to the electrolyte surface. Spatiotemporal phenomena accompany the transition between two stable states or the oscillations during the reaction.
Transition from one state to the other is meditated by the formation of structure at the electrode.

The origin of patterning of the surface in our case is due to different phenomena so called coexisting states $[17,18]$. The reason for these inhomogeneous surface qualities is often explained by overdosage of organic additives during electrodeposition at high current densities under mass transport control. In our case, the inhomogeneity is observed at medium values of the current density, the bright area increasing with the current density. This effect could be explained by so called coexisting states during nickel composite electrodeposition, and is caused by sudden changes in the structure of organic molecules, adsorbed on the electrode surface, depending on the electrode potential. This effect is accompanied by a discontinuity as a characteristic step potential $U_{t}$ in the stationary I-E diagram. If a

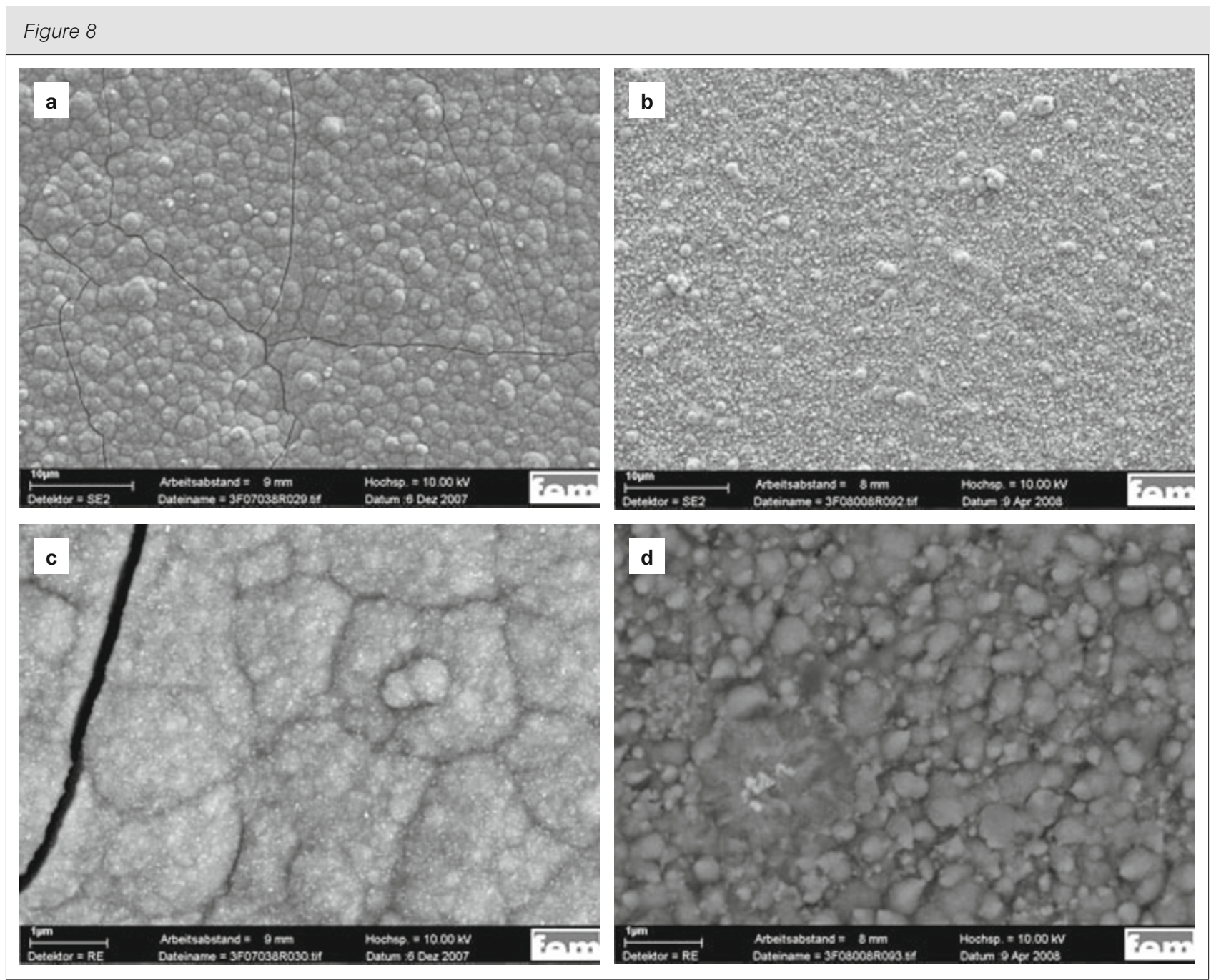

Figure 8 continued on next page 


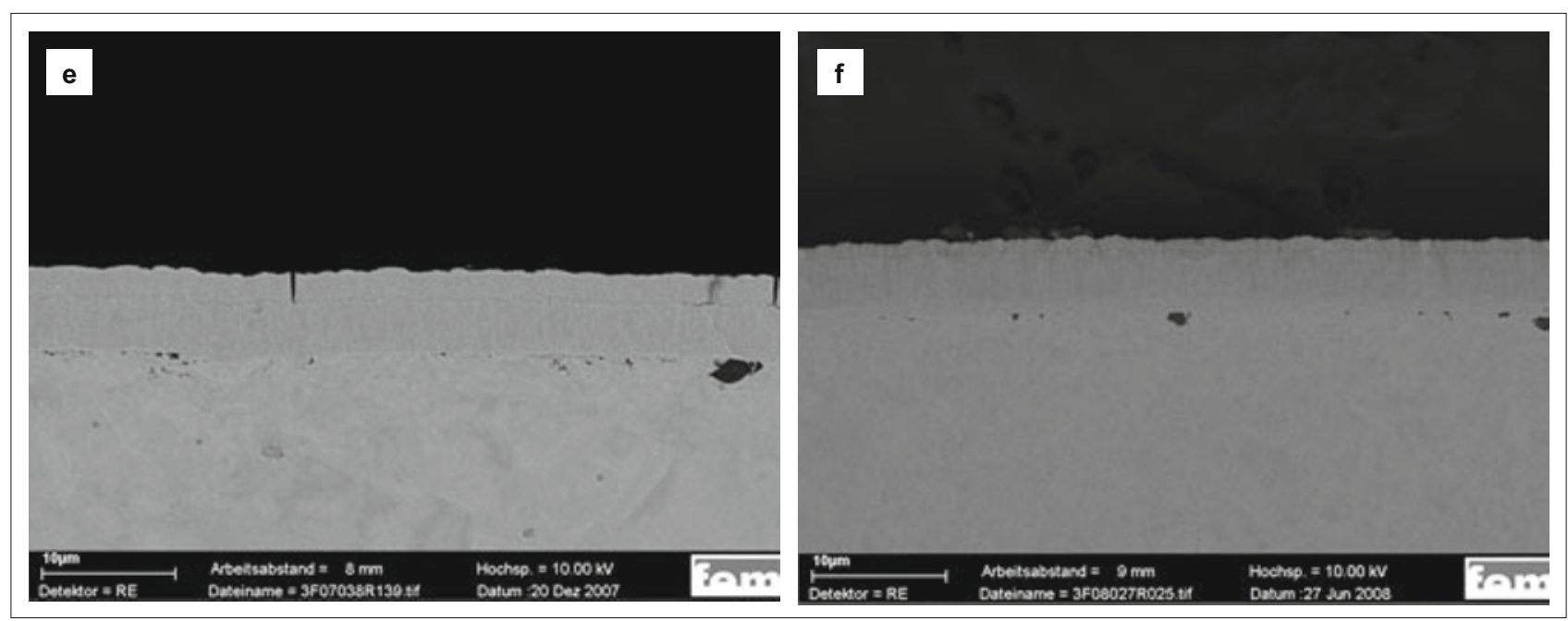

Crack formation at $0.2 \mathrm{~A} / \mathrm{dm}^{2}$ (142 mg Au/g polymer, $\left.1000 \mathrm{rpm}\right)$; a),c),e) : without saccharine; b),d),f): 1 g/l saccharine

constant current density is used during deposition and if this value lies in the region of the discontinuity, then one part of the surface is coated with the current density $I_{A}$, whereas another part is coated with $I_{B}$ (see Figure 7). Along the branches of the I-E-curve a and b, homogeneous coating surfaces are produced. As this homogeneity is preferred in decorative as well as in technical applications, the additive system and the concentrations of the additive components have to be changed, in order to avoid these coexisting states.

\section{Formation of cracks}

The occurrence of tensile stress, which is a problem in many electroplated coatings, may cause the formation of cracks and adhesion problems in the coatings. The additive system for nickel electrolytes is very variable in the control of tensile or compressive stress, and especially the addition of saccharine reduces tensile stress in nickel coatings [19-23]. Other additives like butynediol increase the stress values, so relatively high amounts of saccharine have to be added to the electrolyte solution, in order to balance the internal stress formation. The electrochemical properties of the PEI-PAMAMnano-Au are similar to those of butynediol, so the formation of cracks was observed, induced by high internal stress. As the additive saccharine does not reduce the electrolyte stability of the polymer-nanoAu system, it was possible to use this additive as a stress reducer in order to avoid cracks.

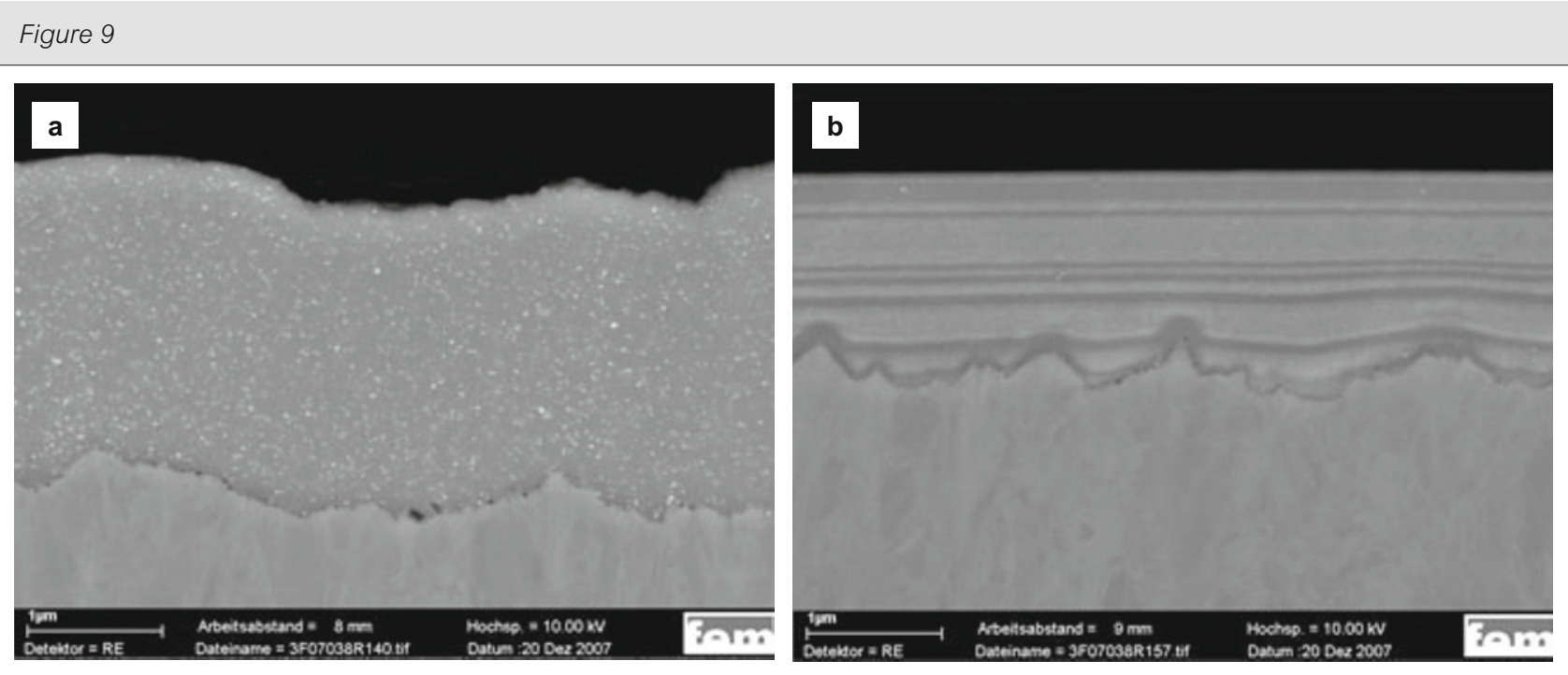

Cross-sections of deposits with different current densities (1000 rpm); a): $0.4 \mathrm{~A} / \mathrm{dm}^{2}, \mathrm{~b}$ ): $8.0 \mathrm{~A} / \mathrm{dm}^{2}$ 


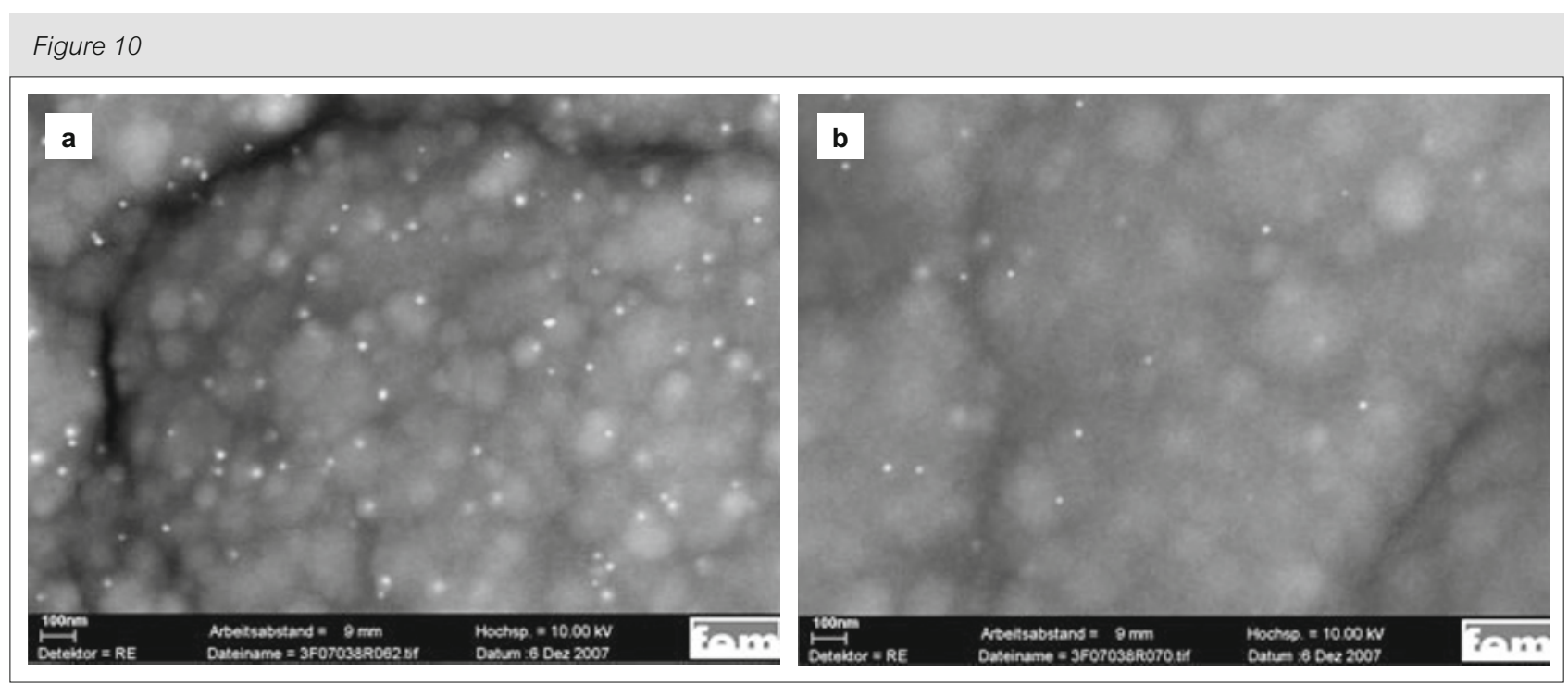

Influence of the current density on the Au incorporation (142 mg Aulg polymer, $1000 \mathrm{rpm}$ ); a) $\left.0.4 \mathrm{~A} / \mathrm{dm}^{2}, \mathrm{~b}\right) 2.0 \mathrm{~A} / \mathrm{dm}^{2}$

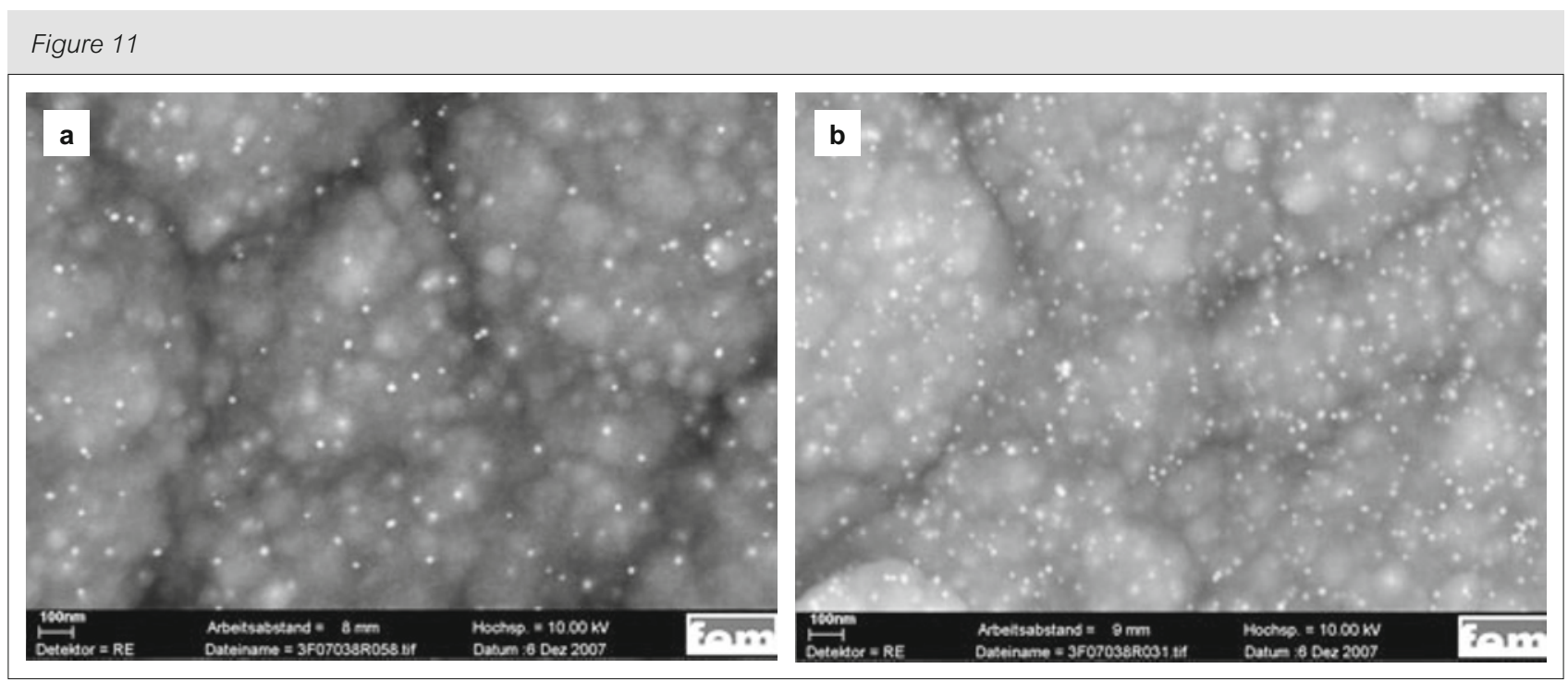

Influence of the gold concentration on the Au incorporation (0.2 A/dm², $1000 \mathrm{rpm}$ ); a) $71 \mathrm{mg} \mathrm{Au/g} \mathrm{polymer,} \mathrm{b)} 142 \mathrm{mg} \mathrm{Au/g} \mathrm{polymer}$

\section{Levelling effect of PEI-PAMAM}

According to the I-E experiments, a levelling effect of the PEI-PAMAM polymer was expected, with or without gold nanoparticles present in the solution, if the electrodeposition takes place under mass transport control. This is supported by cross-sections of samples plated at high current densities $\left(8 \mathrm{~A} / \mathrm{dm}^{2}\right)$ to be seen in Figure 9. At low current densities, the levelling effect is neglectable, the surface roughness of the substrate is reproduced (see Figure 9).

\section{Surface morphology}

Depending on the levelling by the polymer and the applied current density, the surface of the composite coatings are coarse at low current densities, and have a fine-grained structure at higher current densities. The gold nanoparticles are visible in the SEM investigations as very small, bright spots on the surface (see Figure 10). If the ratio of gold and polymer increases, more gold nanoparticles are incorporated. With constant concentrations, the rate of gold incorporation is decreased at higher current densities. This can be explained by the electrochemical behaviour of the polymer-nanogold system, acting like an inhibitor at high current densities, i.e. under mass transport control. In this case, the nickel deposition is preferred against the nano-gold deposition. So it can be concluded that 


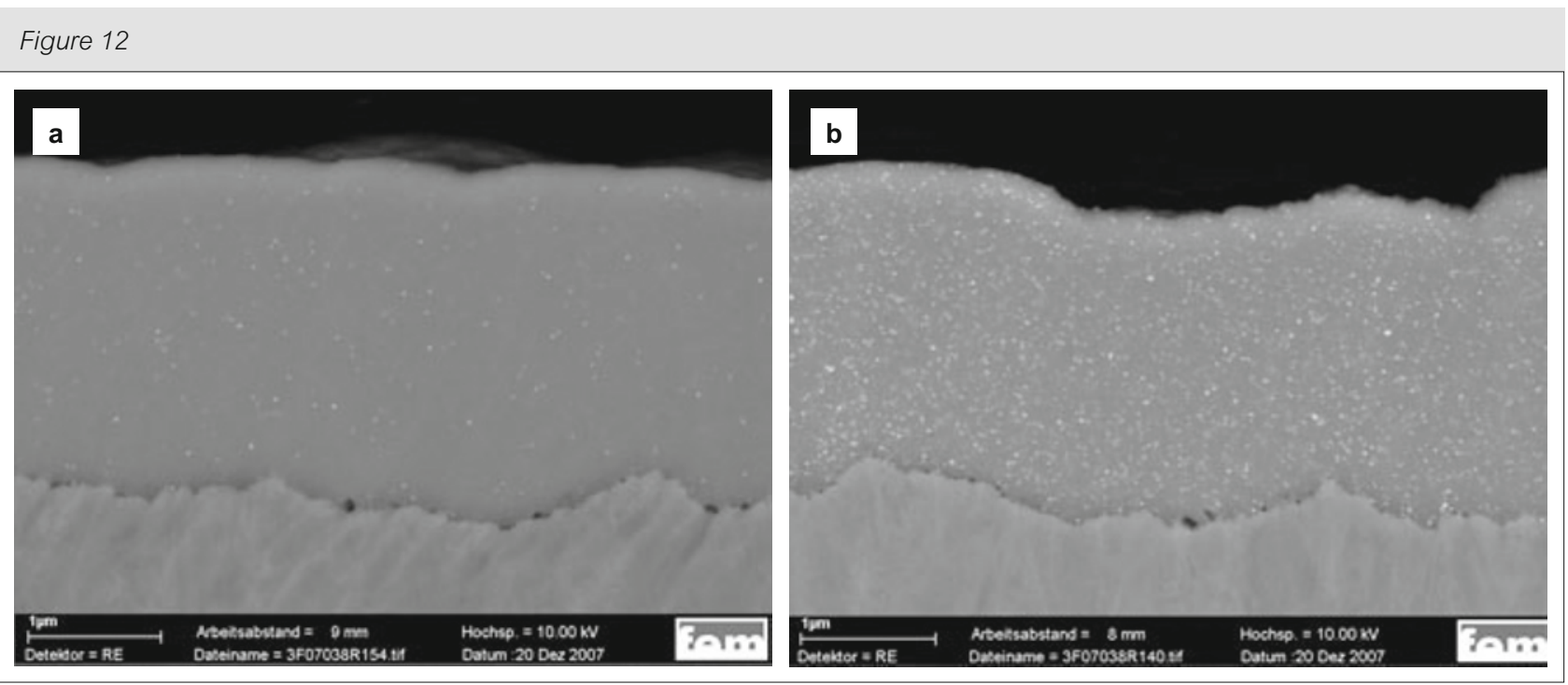

Influence of current density and electrolyte composition on the Au incorporation in cross-section investigations (1000 rpm); a) 0.4 A/dm², $71 \mathrm{mg}$ Au/g polymer, b) $0.2 \mathrm{~A} / \mathrm{dm}^{2}, 142 \mathrm{mg}$ Au/g polymer

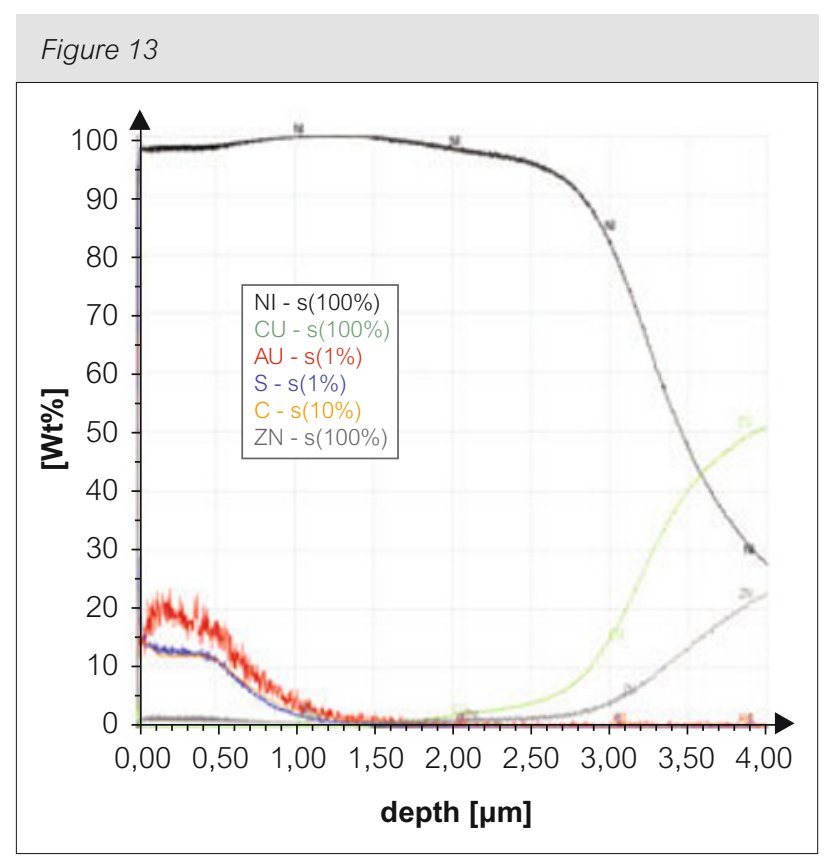

GDOES depth profile of a Ni-matrix-nano-Au composite coating $\left(8.0 \mathrm{~A} / \mathrm{dm}^{2}\right)$ the incorporation of gold nanoparticles is increased with higher polymer-nano-Au concentrations and with a reduction of the diffusion layer at high rotation speeds. An example for the increased incorporation with the polymer-nano-Au concentration is given in Figure 11, showing the increase of the gold incorporation by a double concentration of polymernano-Au. A further increase above the value of 142 mg gold per $\mathrm{g}$ polymer is not possible, because of a reduced stability of the nano-gold system exceeding this value.

\section{Ion beam preparation and cross-sections}

Only with the additional effort of ion beam etching of the metallographic cross-sections, it was possible to exhibit the incorporation of the gold nanoparticles in the nickel matrix. They are not only adsorbed on the layer surface, but also incorporated over the whole layer as it is necessary its function as composite material. As an example for the influence of the applied current density and for the importance of the electrolyte composition, the SEM

Table 3: GDOES analysis of several samples, coated at different current densities

\begin{tabular}{|lllll|}
\hline Current density, A/dm & Nickel, wt.\% & Gold, wt.\% & Carbon, wt.\% & Sulphur, wt.\% \\
\hline 0.2 & 88.2 & 3.4 & 1.0 & 0.2 \\
0.4 & 97.2 & 1.0 & 1.6 & 0.2 \\
1.0 & 95.5 & 2.8 & 1.5 & 0.2 \\
2.0 & 97.4 & 0.6 & 1.6 & 0.4 \\
4.0 & 97.6 & 0.5 & 1.5 & 0.4 \\
8.0 & 98.5 & 0.2 & 1.2 & 0.1 \\
\hline
\end{tabular}




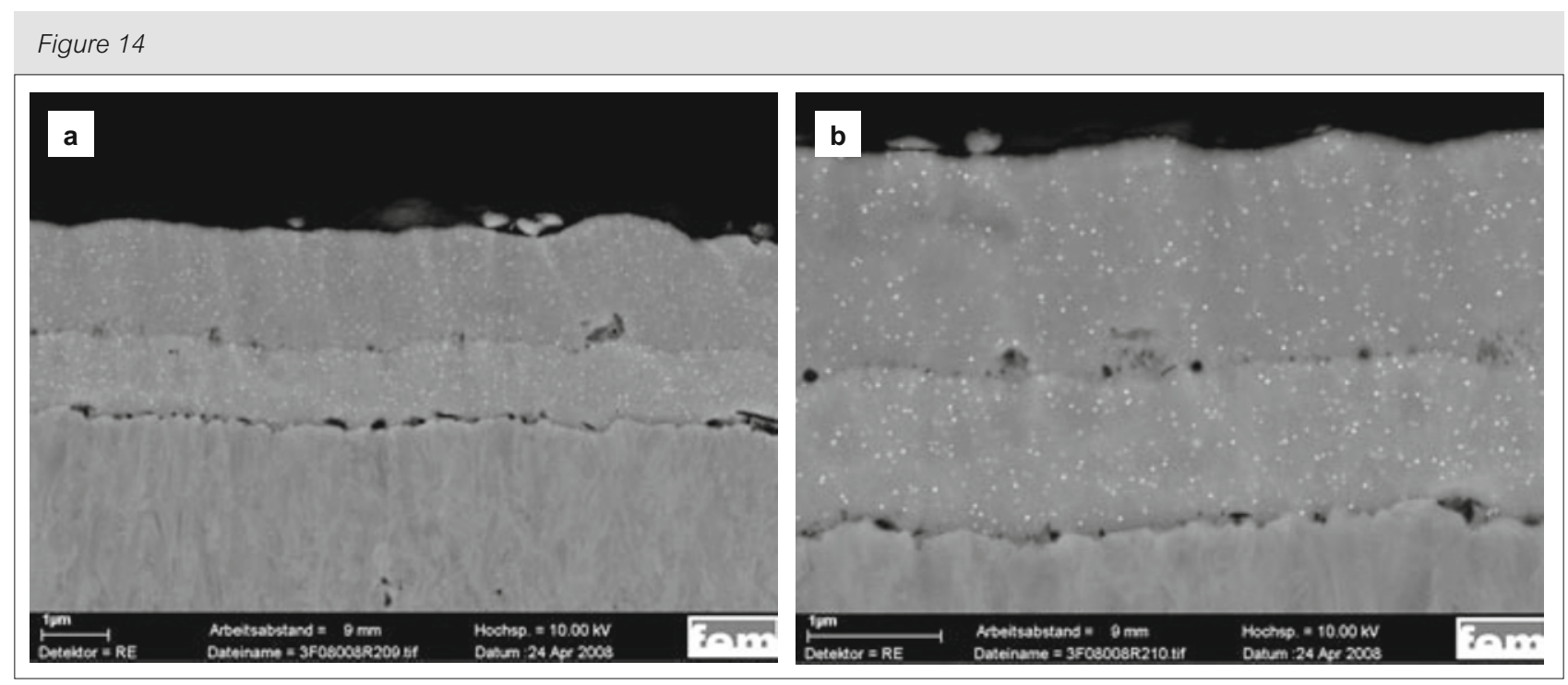

Bilayers of Ni-matrix-nano-Au composite coatings, deposited with different current densities; outer layer $0.4 \mathrm{~A} / \mathrm{dm} \mathrm{m}^{2}$ with $1.8 \% \mathrm{Au}$; inner layer $0.2 \mathrm{~A} / \mathrm{dm}^{2}$ with $2.9 \% \mathrm{Au}$ (71 mg Aulg polymer, $1000 \mathrm{rpm}$ )

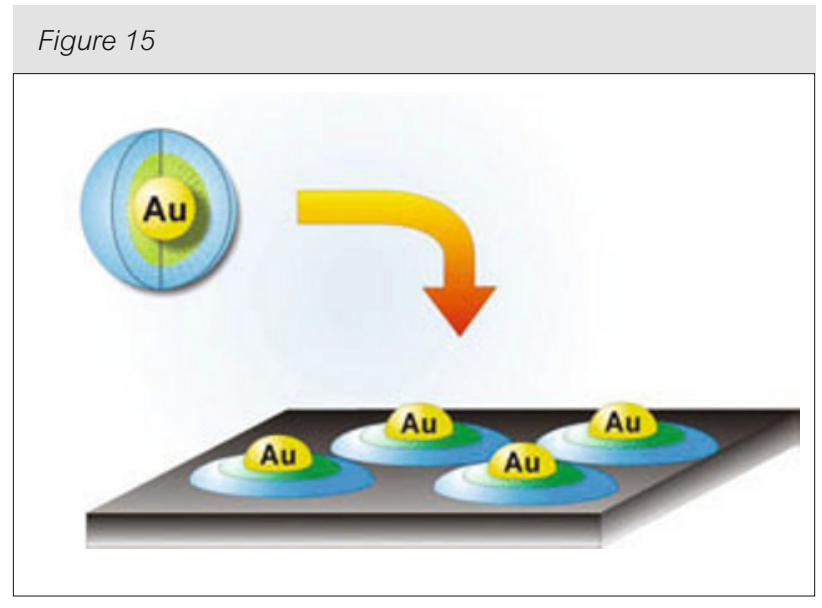

Schematic model for the homogeneous distribution of the gold nanoparticles

pictures are given in Figure 12. With the optimum of the deposition parameters, a very homogeneous incorporation of nanoparticles over the complete nickel layer is observed. As a confirmation of the surface investigations, also the cross-sections show higher gold contents with an increase of the nano-Au concentration in the solution. The highest incorporation is observed at high nano-gold concentrations and low current densities.

\section{GDOES analysis}

Depth profiles of nickel, gold, carbon, and sulphur are the results of the investigations with the glow discharge optical emission spectroscopy (GDOES). The carbon signal is caused by the incorporation of the PEI-PAMAM polymer into the nickel layer, which could be shown by electroplating experiments with the polymer alone. Sulphur is caused by the electrolyte matrix, but the most interesting result is the gold analysis and the course of the gold incorporation along the layer. The optical impression given by the SEM pictures is approved by the quantitative analysis (table 3). The analysis values of the examined samples are average values for the composition and are not completely steady, but show the tendency of high gold contents at low current densities, and less gold incorporation at high current densities. This characteristics is ascribed to the higher probability of incorporation during the slowlier film growth at low current densities. The co-deposition of carbon and sulphur may cause a higher internal stress in the coatings.

The dependence of the gold incorporation on the applied current density is a possible parameter for the control of the gold content in different layers, electroplated from the same electrolyte. Figure 14 shows bilayers of composite coatings, plated at two different levels of current density $\left(0.2 \mathrm{~A} / \mathrm{dm}^{2}\right.$ in the first layer, $0.4 \mathrm{~A} / \mathrm{dm}^{2}$ in the second layer), with a variation of the gold incorporation (2.92 wt.\% vs. 1.85 wt.\%). Also gradient layers may be electrodeposited in the same way.

\section{Schematic model as an explanation for the homogeneous incorporation of gold nanoparticles}

The homogeneous distribution of the metal nanoparticles is caused by the special core shell 
architecture of the polymer system as a nano transporter, keeping the distance between the metal nanoparticles and keeping them from agglomeration. As visualisation of this phenomenon, a model similar to a fried egg was developed (see Figure 15).

The PEI-PAMAM polymer used for these studies, is a hyperbranched polymer with a special architecture. This structure consists of a core, from which multiple polymer branches are spreading out, and a shell with functional groups. The core and the branches are represented by green spheres in Figure 15, the functional groups by blue spheres. The gold nanoparticles are encapsulated in the hyperbranched polymer, similar to the yellow of an egg, encapsulated by egg white. After the transfer of this system into a plating electrolyte, the polymeric shell provides the stability of the metal nanoparticles even at high ionic strengths. In the moment, when the polymer-nanoAu system is reaching the electrode surface during the electroplating process, the three-dimensional structure collapses into a two-dimensional overlay on the electrode caused by a strong adsorption, still providing a ring-like shell, stabilising and keeping the distance between the nanoparticles, which is the reason for the extremely homogeneous distribution of the gold nanoparticles in the nickel matrix.

\section{Conclusion and summary}

By combination of gold nanoparticles with the polymer PEI-PAMAM it is possible to stabilize a clear solution of metal nanoparticles in electrolyte solutions of high ionic strength. The long term stability of the solution depends on the molar ratio between polymer and gold. Only solutions with a molar ratio up to 1:30 showed good long term stability. To investigate the incorporation of nanoparticles into metal layers, the system nickel-gold was used as a demonstrator, because there is no diffusion between nickel and gold. A standard nickel sulphamate electrolyte was used as electrolyte base. The current density was changed between 0.2 and $8 \mathrm{~A} / \mathrm{dm}^{2}$. The gold nanoparticles are very homogeneously distributed on the surface and inside the coatings, as can be seen from ion etched cross-sections. An agglomeration of the nanoparticles with about 10 $\mathrm{nm}$ size was not observed. The gold incorporation of 2-3 wt.\% in the nickel layers was achieved by rather low gold concentrations in the electrolyte of only $70 \mathrm{mg} / \mathrm{l}$ (converted from the pre-solution). With the incorporation of gold nanoparticles into nickel layers, it has been shown, that it is possible to synthesize new metal nanoparticle-metal matrix systems (MNP-
MMS). The characterisation of this and other systems of metal nanoparticles with different matrix metals is subject of further investigations, in order to show that it is possible to reduce the gold consumption by substitution or reduction of top gold layers.

\section{Acknowledgement}

This project was sponsored by the German Federal Environmental Foundation DBU - Deutsche Bundesstiftung Umwelt.

\section{About the authors}

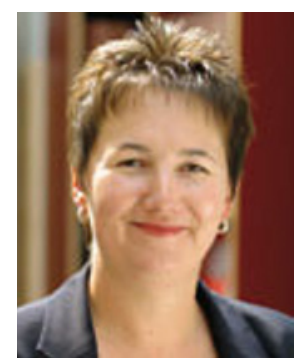

Dr. Renate Freudenberger is a chemist with focus on electroanalytical techniques and chemically modified electrodes, working on R\&D in electroplating companies, and now head of the department of electrochemistry, electroplating, and corrosion at the Forschungsinstitut Edelmetalle \& Metallchemie (fem).

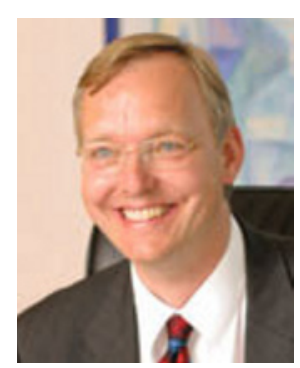

Dr. Andreas Zielonka is Director of the Forschungsinstitut Edelmetalle \& Metallchemie (fem) in Schwäbisch Gmünd, Germany, and has been involved in research and industrial development in the field of electrochemistry, electroplating and corrosion for 30 years.

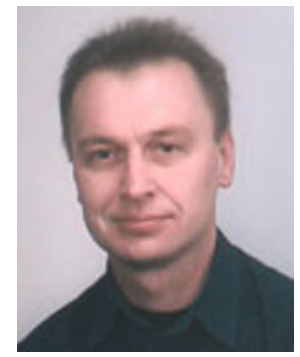

Dipl.-Ing. (FH) Martin Funk is an engineer in the field of material science and surface technology, working since 1989 in the department of electrochemistry, electroplating, and corrosion at the Forschungsinstitut Edelmetalle \& Metallchemie (fem), with the main focus on metallic composite coatings and electroless plating.

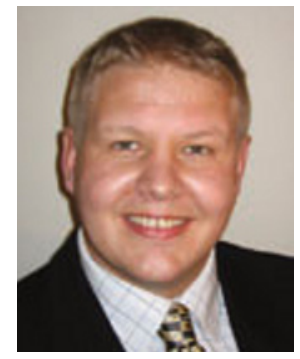

Dr. Paul Servin, nanopartica, Berlin, is a chemist with focus on hyperbranched polymers, metal nanoparticle production and the applications thereof. Currently he is the CEO of nanopartica $\mathrm{GmbH}$ which is a spin-off from FU Berlin. 
Prof. Dr. Rainer Haag obtained his PhD with A. de Meijere at the University of Göttingen in 1995. After postdoctoral at University of Cambridge (UK), and Harvard University (USA), he completed his habilitation at the University of Freiburg in 2002. He then became Associate Professor at the University of Dortmund and in 2004 was appointed full Professor of organic and macromolecular chemistry at the Freie Universität Berlin. His current research interests are functional dendritic architectures, multivalent systems, nanotransporters for dye and drug delivery, and non-fouling surfaces.

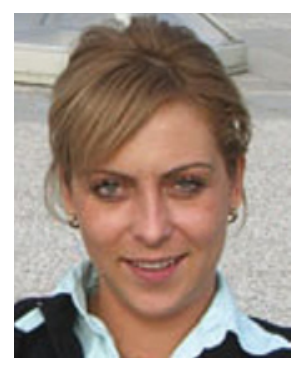

Dr. Teodora Valkova is an engineer in the field of electrochemistry and protection of corrosion, working in the Institute of Physical Chemistry of Bulgarian Academy of Sciences with the main focus of electrodeposition of metal and alloys.

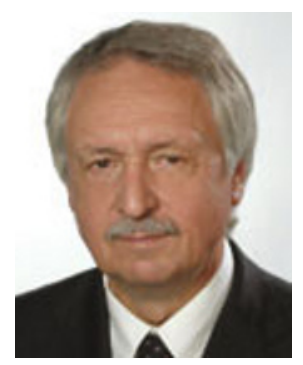

Prof. Dr. Uwe Landau, after his metallurgy studies, obtained his $\mathrm{PhD}$ in electrochemistry, and completed his habilitation at the Technical University Berlin in the field of Surface Technology. This was also the focus of his industrial activities, for 20 years in OTB Oberflächentechnik, and from 2007 in Largentec $\mathrm{GmbH}$, Berlin, a company he founded for the development of bioactive and biocidal surfaces.

\section{Reference}

1 J. Keilitz, M. Radowski, J.D. Marty, R. Haag, F. Gauffre, C. Mingotaud, Chem. Mater., 2008, 20 (7), 2423

2 M. Krämer, Dissertation Albert-Ludwigs-Universität Freiburg, (2004)

3 X. Cai and M. Schell, Electrochem. Acta 37, 673,(1992)

4 X. Yu and M. Schell, J. Phys.Chem 94,7137(1990)

5 P. Strasser, M. Lübke, F. Raspel, M. Eiswirth; G. Ertl, J.Chem. Phys 107, 979(1997)
6 I. Krastev and M. Nikolova, J.Appl.Electrochem., 16 (1986) 875

7 I. Krastev, M. E. Baumgärtner, and Ch. J. Raub, Metalloberfläche, 462 (1992) 63

8 I. Krastev, M. E. Baumgärtner, and Ch. J. Raub, Metalloberfläche, 463 (1992) 115

9 I. Krastev and M. T. M. Koper, Physica A, 213 (1995) 199

10 H. R. Khan, O. Loebich, I. Krastev, and Ch. J. Raub, Trans. Inst. Metal Finish. (UK), 724 (1994) 134

11 I. Krastev, Bulg.Chem.Commun., 29 3/4 (1997) 586

12 S. Nakabayashi, I. Krastev, R. Aogaki, and K. Inokuma, Chemical Physics Letters, 294 (1998) 204

13 S. Nakabayashi, K. Inokuma, A. Nakao, and I. Krastev, Chemistry Letters, (2000) 88

14 I. Krastev, T. Valkova, and A. Zielonka, Journal of Applied Electrochemistry, 3312 (2003) 1199

15 O-Lev, M. Sheintuch, L. Pismen and C. Yarnitzky, Nature 336, 458 (1988)

16 G. Flätgen, K. Krisher, B. Pettinger, K. Doblhofer, H. Junkes and G. Ertl, Sience 269, (1995) 668

17 J. Osterwald, H. Schulte, Galvanotechnik, 87, (1976), 440

18 H. Schulte, Dissertation TU Berlin, (1976)

19 A.Ciszewski, S.Posluszny, G.Milczarek and M.Baraniak, Surface and Coatings Technology 183(2004) 127

20 N.Kaneko, M.Watanabe and H. Nezu, J.Appl. Elctrochem. 24(1994) 227

21 R.Renner and K. Liddell, J.Appl. Elctrochem.32, (2002) 621

22 D. Mockute and G.Bernotiene, Surface and Coatings Technology 135, (2000) 42

23 D. Mockute, G. Bernotiene and R. Vilkaite, Surface and Coatings Technology 160(2002) 152 